\title{
Effect of Inoculation Route on the Production of Antibodies and Histological Characteristics of the Spleen in Laying Hens
}

Technical Note

\section{-Author(s)}

Eto $\mathrm{SF}^{1}$

Andrade FG

Pinheiro $\mathrm{JW}^{2}$

Balarin $\mathrm{MR}^{3}$

Ramos SP4

Venancio $\mathrm{EJ}^{5}$

1 Programa de Pós-graduação em Patologia Experimental - UEL.

2 Departamento de Zootecnia - UEL.

3 Departamento de Medicina Veterinária Preventiva - UEL.

4 Departamento de Histologia - UEL.

5 Departamento de Ciências Patológicas UEL.

\section{Mail Adress}

EJ Venancio
Universidade Estadual de Londrina
Campus Universitário
86051-990
Tel: 33715732
Fax: 33714267
E-mail: emersonj@uel.br

- Keywords

Antibody production, humoral immunity, lgY, laying, spleen.

\section{Acknowledgments}

This study was partially supported by CAPES, Brazil. Eto SF received a fellowship from CNPq, Brazil.

\begin{abstract}
Recent studies have reported the use of $\lg Y$ antibody in the prevention or treatment of diseases in animals. IgY can be obtained in large amounts from the yolk of chicken eggs through a low-cost process. This study evaluated the effect of different routes of inoculation on antibody production and spleen morphological characteristics of laying hens (White Leghorn) inoculated with sheep red blood cells. The analysis of the results showed that the intramuscular route is the most efficient for total antibody production in the primary immune response, while the intravenous route is the most efficient in producing $\lg Y$ antibodies in the secondary immune response. No histological changes were observed in the spleen of laying hens. This study could be useful for developing protocols of antigen inoculation in laying hens for $\lg Y$ antibody production.
\end{abstract}

\section{INTRODUCTION}

The main class of immunoglobulins that occurs in chickens is $\lg Y$ (Warr et al., 1995). It is found in high concentrations in the egg yolk and its structural and functional features are similar to those of mammalian IgG (Dias da Silva \& Tambourgi, 2011; Taylor et al., 2009). For instance, the Fc region of $\lg Y$ is responsible for its biological functions, such as complement fixation and opsonization (Warr et al., 1995). Compared with antibody production in mammals, IgY from the yolk of chicken eggs has several advantages, including the possibility of large scale production without bleeding or sacrificing the chicken and the lack of reactivity with the complement system or immunoglobulin receptors of mammals (Dias da Silva \& Tambourgi, 2010; Xiao \& Gao, 2010). Furthermore, several studies have investigated the usefulness of $\lg Y$ antibodies in the prevention or treatment of diseases in animals (Vega et al., 2011; Xu et al., 2011).

The route of inoculation is a critical point in immunization and for antibody production in mammals and birds (Fyfe et al., 1991; Kreukniet et al., 1992; Boa-Amponsem et al., 2006). Moreover, the route of inoculation influences the class of antibodies produced (Hu et al., 2007). Thus, identifying the optimal route of antigen inoculation in laying hens could result in new technologies based on IgY antibodies for the diagnosis, prevention and treatment of disease in humans and animals.

This study investigated the effect of the inoculation route on antibody production and spleen histological characteristics of laying hens inoculated with sheep red blood cells.

\section{MATERIAL AND METHODS}

Sixteen 45-week-old laying hens (White Leghorn) were randomly 
assigned to four groups ( $\mathrm{n}=4$ /group) and maintained in individual cages at ambient temperature, receiving water and feed (Purina, Brazil) ad libitum. Control (c) group chickens were inoculated with PBS pH 7.2 (250 $\mu \mathrm{l})$, while each bird of the intravenous (iv), intramuscular (im) or subcutaneous (sc) groups was inoculated with $2.5 \%$ sheep red blood cells (SRBC) in PBS pH 7.2 (250 $\mu l)$. SRBC inoculation was performed in the brachial vein (iv group), the breast muscle (im group), or the right wing (sc group).

All chickens were inoculated on days 1 and 28, and sera samples were obtained before the first inoculation and on days 7 and 35. The birds were sacrificed on day 35 and their spleens were collected and processed, as previously described by Beçak \& Paulete (1970). Antibody titers against SRBC were determined as described in Boa-Amponsem etal., 2001. Morphometric analysis of the spleen was performed by image analysis (MOTICAN, Motic Company, Xiamen, China) using an optical microscope at $100 \mathrm{X}$ (germinal centers) and $400 X$ (areas of white and red pulp) magnifications. The germinal centers were counted on five slices per bird. Ten images per slice from each chicken were analyzed to determine the areas of white and red pulp. The experimental procedures were approved by the Ethics Committee for Animal Research of the Londrina State University (Universidade Estadual de Londrina).

Normality distribution was assessed by the ShapiroWilk's test; the significance level was set at $p<0.05$ for non-normalized data. Intergroup differences were analyzed by means of ANOVA and the post hoc Tukey's test (parametric data) or Kruskal-Walli's and post hoc Dunn's test (nonparametric data), with differences considered significant when $p<0.05$.

\section{RESULTS}

Regarding the primary response (day 7), the im and Sc groups presented increased total antibody production; however, neither the IgM nor IgY titers increased significantly, regardless of the route analyzed.

Considering the secondary immune response (day 35), analysis verified a significant increase in total antibody titers in the iv, im and sc groups compared with the controls. Furthermore, the total antibody titers of the iv group were increased compared to the sc, but not the im group. Regarding the IgY antibody titers, increased levels in the iv group were observed in relation to the remaining groups. The levels of IgM antibodies showed a significant difference only between the control and im groups (Figure 1).
Histological analysis of the spleen following the 2nd inoculation of SRBC showed no differences in the areas of red and white pulp (Figure 2). No significant differences occurred in the number of germinal centers (Figure 2).
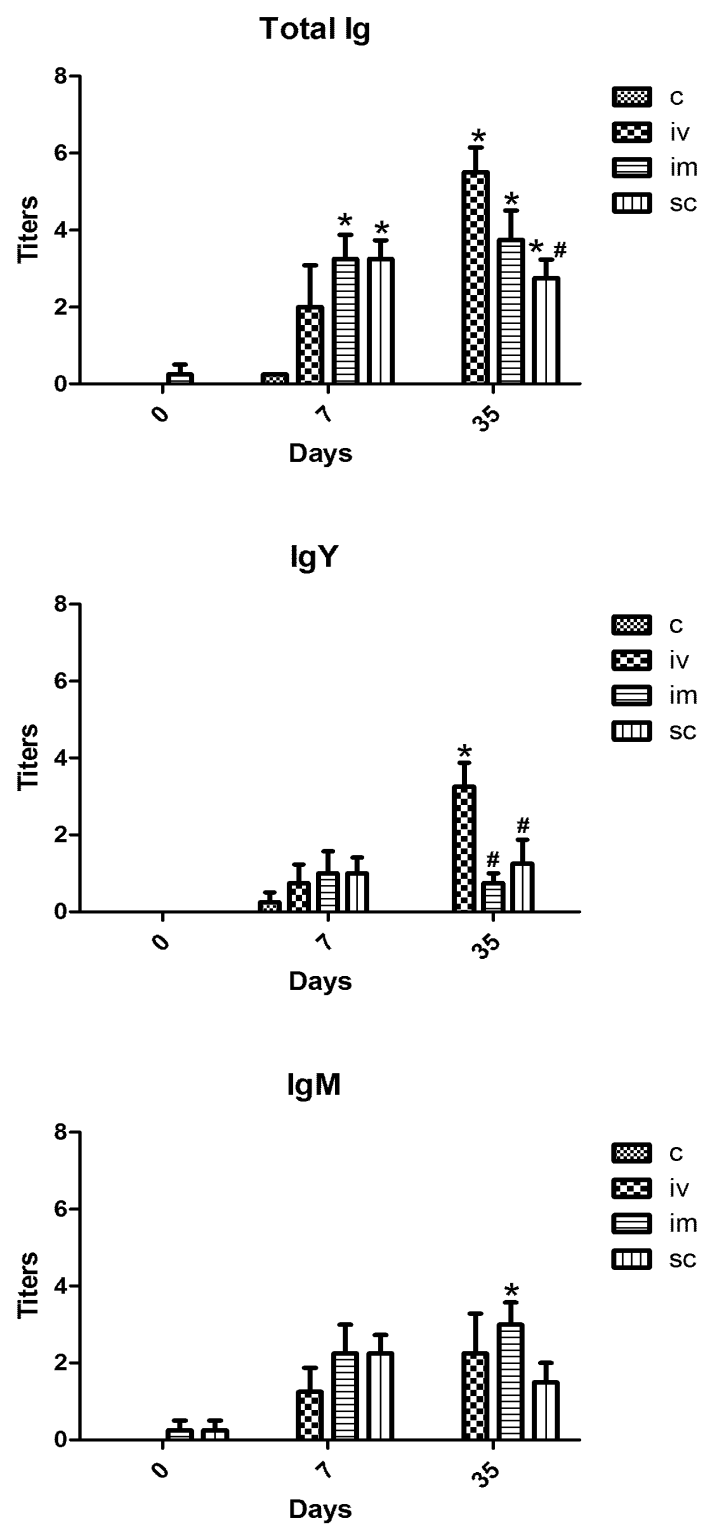

Figure 1 - Total antibodies, IgY and IgM anti-SRBC in the serum of laying hens after immunization with SRBC. Data are expressed as the mean $( \pm$ SEM) of the reciprocal of the serum titer. * means differ significantly from the control group $(p<0.05$, ANOVA, Tukey's test). \# means differ significantly from the iv group ( $p$ $<0.05$, ANOVA, Tukey's test).

\section{DISCUSSION}

The capacity for antibody production can be influenced by several factors, including the inoculation route (Mozdzanowska et al., 2007; Kreukniet et al., 1992; Muir et al., 1998). In the present study, for the 

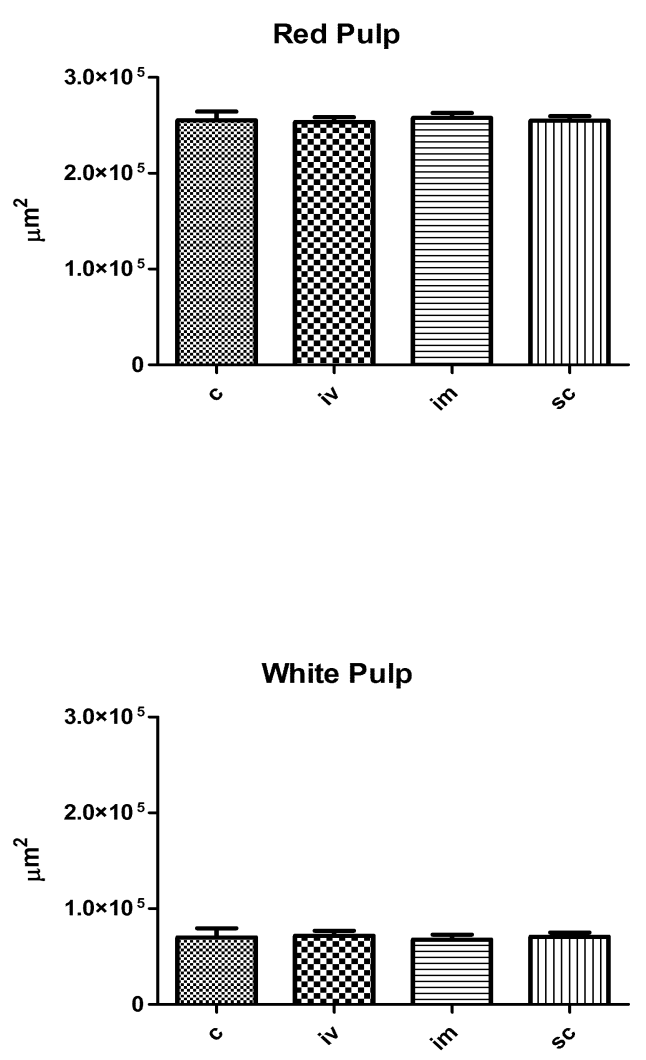

CG

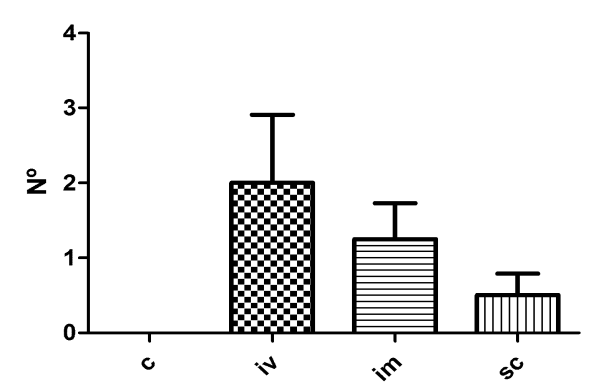

Figure 2 - Histological analysis of areas of red and white pulp and the number of spleen germinal centers of the laying hens after immunization with SRBC.

primary immune response, the im and sc routes led to a significant increase in total antibody levels compared to the iv route. These results suggest that the im and sc routes were more efficient than the iv route for primary immune response induction. These results are in disagreement with those obtained by Boa-Amponsem et al. (2001), who observed higher antibody titers against SRBC by iv than im inoculation. However, consistent results were obtained in White Leghorn chickens selected for high antibody production. In that same study, observation showed that White Leghorn chickens selected for low antibody production showed no differences in antibody production in relation to inoculation route (Boa-Amponsem et al., 2001).

Regarding the secondary immune response, the iv route resulted in higher total antibody titers than the sc route. The difference in the total antibody levels was mainly due to increased levels of IgY. However, chickens from the im group also presented increased total antibody titers, and this difference was caused by $\lg M$ antibody titers, rather than increases in $\lg Y$ antibody levels, as expected for secondary immune response (Freitas et al., 2011). The predominance of IgM in the secondary immune response was also observed in chickens selected for low antibody production (BoaAmponsem et al., 2001). These results suggest that the effectiveness of the routes studied is different in primary and secondary responses and that the iv route seems to provide better performance in the second immunization.

Since the iv route delivers antigens to the spleen lymphoid tissues, the primary site of antibody production after immunization by this route (White et al., 1975), analysis of morphological changes in the spleen of the inoculated birds was performed. No significant changes were detected in the spleens of the birds inoculated with $2.5 \%$ SRBC, independently of the route used, probably because the concentration of SRBC was not sufficient to stimulate significant changes in the spleen. Other secondary lymphoid tissues could also contribute to lgY production.

In summary, this study demonstrated that the inoculation route influences both the antibody levels and the class of antibodies produced by laying hens. These results could be meaningful for establishing protocols for the inoculation of laying hens to produce antibodies.

\section{REFERENCES}

Beçak W, Paulete J. Técnicas de Citologia e Histologia. São Paulo: Nobel; 1970.

Boa-Amponsem K, Picard M, Blair ME, Meldrum B, Siegel PB. Memory antibody responses of broiler and leghorn chickens as influenced by dietary vitamin $E$ and route of sheep red blood cell administration. Poultry Science 2006; 85(2):173-7.

Boa-Amponsem K, Price SEH, Dunnington EA, Siegel PB. Effect of route of inoculation on humoral immune response of white leghorn chickens selected for high or low antibody response to sheep red blood cells. Poultry Science 2001; 80(8):1073-1078.

Dias da Silva W, Tambourgi DV. IgY: a promising antibody for use in immunodiagnostic and in immunotherapy. Veterinary Immunology and Immunopathology 2010; 135(3-4):173-180.

Fyfe L, Maingay J, Robinso AC, Howie SE. Murine immune response to 
HIV-1 p24 core protein following subcutaneous, intraperitoneal and intravenous immunization. Immunology 1991; 74(3):467-472.

Freitas JA, Vanat N, Pinheiro JW, Balarin MR, Sforcin JM, Venancio EJ. The effects of propolis on antibody production by laying hens. Poultry Science 2011; 90(6):1227-1233.

Hu H, Lu X, Tao L, Bai B, Zhang Z, Chen Y, Zheng F, Chen J, Chen Z, Wang $\mathrm{H}$. Induction of specific immune responses by severe acute respiratory syndrome coronavirus spike DNA vaccine with or without interleukin-2 immunization using different vaccination routes in mice. Clinical and Vaccine Immunology 2007; 14(7):894-901.

Kreukniet MB, van der Zijpp AJ, Nieuwland MGB. Effects of route of immunisation, adjuvant and unrelated antigens on the humoral immune response in lines of chickens selected for antibody production against sheep erythrocytes. Veterinary Immunology and Immunopathology 1992; 33(1-2):115-127.

Mozdzanowska K, Zharikova D, Cudic M, Otvos L, Gerhard W. Roles of adjuvant and route of vaccination in antibody response and protection engendered by a synthetic matrix protein 2-based influenza $A$ virus vaccine in the mouse. Virology Journal 2007; 4:118.

Muir WI, Bryden WL, Husband AJ. Evaluation of the efcacy of intraperitoneal immunization in reducing Salmonella typhimurium infection in chickens. Poultry Science 1998; 77(12):1874-1883.

Taylor Al, Fabiane SM, Sutton BJ, Calvert RA. The crystal structure of an avian IgY-Fc fragment reveals conservation with both mammalian IgG and IgE. Biochemistry 2009; 48(3):558-562.

Vega C, Bok M, Chacana P, Saif L, Fernandez F, Parreño V. Egg yolk IgY: protection against rotavirus induced diarrhea and modulatory effect on the systemic and mucosal antibody responses in newborn calves. Veterinary Immunology and Immunopathology 2011; 142 (3-4):156169.

White RG, Henderson DC, Eslami MB, Nielsen KH. Localization of a protein antigen in the chicken spleen. Effect of various manipulative procedures on the morphogenesis of the germinal center. Immunology 1975; 28(1):1-21.

Warr GW, Magor KE, Higgins DA. IgY: clues to the origins of modern antibodies. Immunology Today 1995; 16(8):392-398.

Xiao Y, Gao X. Use of IgY antibodies and semiconductor nanocrystal detection in cancer biomarker quantitation. Biomarkers in medicine 2010; 4(2):227-239

Xu Y, Li X, Jin L, Zhen Y, Lu Y, Li S, You J, Wang L. Application of chicken egg yolk immunoglobulins in the control of terrestrial and aquatic animal diseases: a review. Biotechnology Advances 2011; 29(6):860-868. 